\title{
Nursing care of a patient with sarcoidosis. Case study using ICNP ${ }^{\circledast}$
}

\author{
Pielęgnowanie chorego zsarkoidozą. Studium przypadku zzastosowaniem ICNP®
}

\section{Jakub Brzeźnicki, Hanna Grabowska}

\author{
Pracownia Teorii i Podstaw Pielęgniarstwa, Instytut Pielęgniarstwa i Położnictwa, WNoZ z IMMiT, GUMed \\ CORRESPONDING AUTHOR/AUTOR DO KORESPONDENCJI: \\ Hanna Grabowska \\ Pracownia Teorii i Podstaw Pielęgniarstwa, Instytut Pielęgniarstwa i Położnictwa WNoZ z IMMiT, GUMed/ \\ Laboratory of Basic Nursing, Institute of Nursing and Midwifery, Faculty of Health Sciences with Institute of Maritime and Tropical \\ Medicine, Medical University of Gdańsk \\ ul. Dębinki 7/15, 80-210 Gdańsk \\ e-mail: hanna.grabowska@gumed.edu.pl
}

STRESZCZENIE

Słowa kluczowe:

\section{ABSTRACT}

Key words:
PIELEGNOWANIE CHOREGO Z SARKOIDOZA. STUDIUM PRZYPADKU Z ZASTOSOWANIEM ICNP

Wprowadzenie. Sarkoidoza jest rzadką, wielonarządową chorobą o nieznanej etiologii, charakteryzującą się powstawaniem ziarniniaków głównie w układzie oddechowym.

Cel pracy. Celem pracy jest przedstawienie planu opieki nad chorym z sarkoidozą z uwzględnieniem Międzynarodowej Klasyfikacji Praktyki Pielęgniarskiej ICNP ${ }^{\oplus}$.

Materiał i metody. Badanie zostało przeprowadzone w kwietniu 2019 roku na Oddziale Chorób Wewnętrznych 7 Szpitala Marynarki Wojennej w Gdańsku i objęto nim 54. letniego chorego hospitalizowanego z powodu sarkoidozy. W badaniach zastosowano studium indywidualnego przypadku, technikę wywiadu, obserwacji, pomiarów oraz analizy dokumentacji medycznej pacjenta. W ocenie statusu chorego wykorzystano skale C-HOBIC.

Wyniki i wnioski. Powodem zgłoszenia się pacjenta do szpitala były utrzymujące się od kilku dni stany podgorączkowe, rumień oraz bóle stawów. W wyniku przeprowadzonej oceny i analizy statusu pacjenta sformułowano 7 charakterystycznych dla sarkoidozy diagnoz pielęgniarskich, obejmujących: ból stawów, duszność funkcjonalną, gorączkę, zaburzony czynny zakres ruchu, zmęczenie, ryzyko efektu ubocznego leku i brak wiedzy o chorobie oraz 2 diagnozy wynikające ze stylu życia chorego: nadużywanie tytoniu oraz nadwagę. W planowaniu opieki uwzględniono kluczowe dla ww. diagnoz interwencje, dotyczące monitorowania symptomów i wskaźników zdrowotnych chorego oraz oceny jego wiedzy, a także udział pielęgniarki w procesie terapeutycznym. Słownik ICNP® posiada wystarczający zasób terminów, umożliwiających stworzenie satysfakcjonującego planu opieki pielęgniarskiej nad chorym z sarkoidozą.

sarkoidoza, opieka pielęgniarska, słownik ICNP ${ }^{\oplus}$

Introduction. Sarcoidosis is a rare, multi-organ disease of unknown etiology, characterized by the formation of granulomas mainly in the respiratory system.

Aim. The aim of the study is to present a plan of care for patients with sarcoidosis, including International Classification for Nursing Practice - ICNP ${ }^{\circledast}$ terminology.

Material and methods. The study was conducted in April 2019 at the Internal Disease Unit of the $7^{\text {th }}$ Polish Navy Hospital in Gdansk, and included a 54-year-old patient hospitalized for sarcoidosis. The research employed the case study method and the technique of the interview, observation, analysis of medical records and measurements. The C-HOBIC data set was used to assess the patient's condition. Results and conclusions. The reasons for the patient's admission to the hospital were a continued raised temperature, erythema, as well as joint pain. The assessment and analysis of a patient's status allowed us to formulate seven nursing diagnoses characteristic for sarcoidosis, which included: arthritis pain, functional dyspnoea, fever, impaired active range of motion, fatigue, risk for medication side effect and lack of knowledge of disease and 2 diagnoses resulting from the lifestyle of the patient: tobacco abuse and overweight. The process of nursing care planning included interventions fundamental for the above-mentioned diagnoses. They concerned the monitoring of symptoms and health indices, the patient's knowledge, as well as the role of the nurse in the therapeutic process. The ICNP dictionary includes a sufficient range of terms, which allows the creation of a satisfactory nursing care plan for a patient with sarcoidosis. 


\section{INTRODUCTION}

Sarcoidosis is a rare inflammatory disease of an unknown etiology, which is characterised by the formation of granulomas in multiple organs. It probably develops as a result of interactions between environmental and genetic factors. The lesions most commonly involve the respiratory system, leading to dyspnoea, coughing, the bilateral enlargement of hilar lymph nodes and occasionally chest pain. Apart from the dominating pulmonary form of sarcoidosis, lesions may also appear in the peripheral lymph nodes, joints, liver, heart, kidneys, visual system, skin, salivary glands and nervous system. In the early stages of the disease, many patients experience spontaneous remission. The peak age of onset is between the second and the fourth decades of life. The incidence of sarcoidosis in Poland is estimated at approximately 10 cases per 100 thousand citizens (the worldwide incidence is 1-64/100 000 the highest incidence is observed in Scandinavian countries and among Afro-Americans in the USA, while the lowest is found in Singapore and Japan) [1-5].

Glucocorticosteroids play a key role in the therapy of sarcoidosis, and prednisone is considered to be the first line agent for patients diagnosed with this condition. Biopharmaceuticals and cytostatics are also used in this therapy. Despite the introduction of treatment, the disease becomes chronic in some patients and leads to death in $5 \%$ of cases $[1,3]$.

Apart from participation in the realisation of the therapeutic plan, showing support to the patient and his/her relatives, providing health education and encouraging the patient to collaborate in the therapeutic process are all of fundamental importance in nursing care $[6,7]$.

\section{AIM}

The aim of this paper is to present a plan of nursing care for a patient with sarcoidosis in the context of the International Classification for Nursing Practice (ICNP).

\section{MATERIALS AND METHODS}

An individual case study was used along with different techniques of patient data-gathering. These included anamnesis, observation, measurements and analysis of the patient's medical records. The patient's status was assessed using i.e. standardised scales, such as C-HOBIC.

The study was performed in April 2019 in the Department of Internal Diseases, $7^{\text {th }}$ Naval Hospital, Gdansk, Poland. A 54-year-old male patient, admitted due to sarcoidosis, was enrolled to participate in the study. Before the patient was enrolled, he was informed of the aim of the study and assured of the anonymity of the obtained information. The patient gave his informed consent to participate in the study. The study was also approved by the hospital commandant.

\section{Case report}

The patient reported to the hospital due to a low-grade fever that persisted for several days, and erythema nodosum localised on both his legs and upper left extremity, accompanied by joint pain.

Findings on admission: heart rate $80 \mathrm{bpm}$ (regular, high-tension pulse), arterial blood pressure 135/86 $\mathrm{mmHg}$, body temperature $37.7 \mathrm{oC}$, body mass $99 \mathrm{~kg}$ and body height $175 \mathrm{~cm}$. The BMI was calculated $(32 \mathrm{~kg} / \mathrm{m} 2)$. The patient claimed not to have allergies and declared that he was a smoker (for 15 years).

Other findings:

- respiratory system - 14 breaths per minute, regular rate, abdominal breathing pattern, no engagement of auxiliary respiratory muscles;

- musculoskeletal system - joint pain (4/10 points), limited mobility of hand joints;

- alimentary tract and genitourinary system - no abnormalities.

The patient was auto- and allopsychically orientated, with a normal mood. He reported slight anxiety associated with admission to the hospital. His skin was clean and appeared looked after, warm and moist. The patient is professionally active, and lives with his family. He described his social conditions as satisfactory. The patient is able to look after himself in terms of daily activities.

The analysis of C-HOBIC scales [8,9] revealed: minimal fatigue, dyspnoea, which was absent at rest and occurred during moderate activity. He claimed not to have nausea or to have fallen down in the previous 90 days. His readiness for discharge and therapeutic self-care were assessed: lack of knowledge about the aim of the therapy, moderate orientation in other areas.

The diagnostic process included bronchofiberoscopy (reddening of the mucosa of the upper left bronchus), abdominal ultrasound (increased liver echogenicity with signs of grade 1 steatosis), computed tomography of the chest (enlarged hilar and mediastinal lymph nodes, nodular lesions in the pulmonary parenchyma with a distribution pattern typical for sarcoidosis), heart ultrasound (slight right ventricular hypertrophy), blood test for Yersinia enterocolica IgA (2.3, positive $>1.1)$, as well as ECG and chest X-ray (no worrying findings). The patient was eventually diagnosed with nodular pulmonary sarcoidosis with Löfgren syndrome. The patient received the following oral medication: Apo-Napro (naproxen, $250 \mathrm{mg}$, b.i.d.), Metypred (methylprednisolone, $8 \mathrm{mg}$, q.d.) and Controloc (pantoprazole, $20 \mathrm{mg}$, q.d.).

\section{Plan of nursing care in the context of the ICNP}

In this paper we used the current (2019) version of the dictionary containing reference terminology of the International Classification for Nursing Practice [10].

Diagnosis 1. Arthritis Pain [10047104]

Interventions: Assessing Pain [10026119]; Managing Pain [10011660]; Administering Pain Medication [10023084]; Teaching About Pain [10039115]; Nurse Controlled Analgesia [10039798]

Expected outcome: No Pain [10029008] 
Diagnosis 2. Functional Dyspnoea [10029414]

Interventions: Assessing Respiratory Status [10036786]; Monitoring Respiratory Status [10012196]; Encouraging Rest [10041415]; Teaching Breathing Technique [10039213]; Positioning Patient [10014761]

Expected outcome: No Dyspnoea [10029264]

\section{Diagnosis 3. Fever [10041539]}

Interventions: Measuring Body Temperature [10032006]; Monitoring Body Temperature [10012165]; Teaching About Measuring Body Temperature [10044738]; Administering Antipyretic [10037248]; Managing Fever [10041721]

Expected outcome: Body Temperature Within Normal Limits [10027652]

Diagnosis 4. Impaired Active Range Of Motion [10052095]

Interventions: Assessing Active Range of Motion [10040044]; Promoting Exercise [10040834]; Reinforcing Muscle or Joint Exercise Technique [10036512]; Promoting Adherence To Exercise Regime [10041628]

Expected outcome: Effective Active Range Of Motion [10052082]

\section{Diagnosis 5. Fatigue [10000695]}

Interventions: Assessing Fatigue [10026086]; Managing Fatigue [10046289]; Encouraging Rest [10041415]; Assessing Capabilities [10026040]

Expected outcome: Reduced Fatigue [10029390]

Diagnosis 6. Risk For Medication Side Effect [10037604]

Interventions: Assessing Risk For Adverse Medication Interaction [10045940]; Monitoring Response To Treatment [10032109]; Teaching About Medication Side Effects [10044614]

Expected outcome: No Medication Side Effect [10040295]

Diagnosis 7. Lack Of Knowledge Of Disease [10021994]

Interventions: Assessing Knowledge Of Disease [10030639]; Teaching About Disease [10024116]; Assessing Response To Teaching [10024279]

Expected outcome: Knowledge Of Disease [10023826]

Diagnosis 8. Tobacco Abuse [10022247]

Interventions: Assessing Tobacco Use [10038606]; Teaching About Tobacco Use [10038843]; Counselling About Tobacco Use [10031058]; Teaching About Smoking Cessation [10038647]; Establishing Smoking Cessation Date [10038827]

Expected outcome: No Tobacco Abuse [10029147]

Diagnosis 9. Overweight [10027300]

Interventions: Weighing Patient [10033323]; Monitoring Weight [10032121]

Teaching About Effective Weight [10033001]

Expected outcome: Weight Within Normal Limits

\section{DISCUSSION}

As early as in 1946 Sven Löfgren found that lymph node enlargement, erythema nodosum, joint changes and elevated body temperature may be present in the early phase of sarcoidosis $[1,3,5]$. Our patient manifested the full spectrum of these symptoms.

Although spontaneous remission is observed in many patients, some may develop complications including lung, eye (vision loss, cataract or glaucoma), heart (arrhythmia) or nerve injury [11-14]. The ordered diagnostic workup confirmed the presence of disturbances which mainly affected the respiratory system, liver and heart. The nursing personnel who took care of the patient during his hospital stay were to prepare the patient for these tests and accompany him during them, as well as to implement the therapeutic plan.

Being a disease with an uncertain long-term prognosis, sarcoidosis may have a negative impact on a patient's mental status, promoting the development of depression and a reduced quality of life, as well as leading to chronic fatigue $[15,16]$. Some associate the presence of the above-mentioned problems with a low socio-economic status of such patients [17]. Despite the fact that the given patient presented a normal mood and declared that he received support from his relatives, he still reported fatigue and anxiety associated with the need to stay in hospital.

Individualised and holistic nursing care of a patient diagnosed with sarcoidosis should take into account the clinical manifestation and stage of the disease, the diagnostic and therapeutic plan, as well as the self-care abilities of the patient, the risk of developing complications, and an improvement in the quality of life.

\section{CONCLUSIONS}

The assessment and analysis of a patient's status allowed us to formulate seven nursing diagnoses characteristic for sarcoidosis, which included: arthritis pain, functional dyspnoea, fever, impaired active range of motion, fatigue, risk for medication side effect and lack of knowledge of disease and 2 diagnoses resulting from the lifestyle of the patient: tobacco abuse and overweight.

The process of nursing care planning included interventions fundamental for the above-mentioned diagnoses. They concerned the monitoring of symptoms and health indices, the patient's knowledge, as well as the role of the nurse in the therapeutic process.

The ICNP dictionary includes a sufficient range of terms, which allows the creation of a satisfactory nursing care plan for a patient with sarcoidosis. 


\section{Pielęgnowanie chorego z sarkoidozą. Studium przypadku z zastosowaniem ICNP ${ }^{\circledR}$}

\section{WPROWADZENIE}

Sarkoidoza to rzadka choroba zapalna o nieznanej etiologii, charakteryzująca się tworzeniem ziarniniaków wielonarządowych. Prawdopodobnie sarkoidoza rozwija się w wyniku interakcji między czynnikami środowiskowymi i genetycznymi. Najczęściej zmiany obejmują układ oddechowy, powodując pojawienie się duszności, kaszlu, obustronnego powiększenia węzłów chłonnych wnęk płucnych oraz czasami bólu w klatce piersiowej. Poza dominującą postacią płucną, w przebiegu sarkoidozy pojawić się mogą zmiany w zakresie obwodowych węzłów chłonnych, stawów, wątroby, serca, nerek, narządu wzroku, skóry, ślinianek oraz układu nerwowego. W początkowym stadium u chorych obserwuje się często samoistne remisje. Szczyt zachorowań przypada na 2-4 dekadę życia. W Polsce zapadalność na sarkoidozę wynosi około 10 przypadków na 100 tys. mieszkańców (na świecie 1-64/100 tys. - najwyższą zapadalność obserwuje się w krajach skandynawskich i wśród Afroamerykanów w USA, a najniższą w Singapurze i Japonii) [1-5].

Istotna w terapii sarkoidozy jest podaż glikokortykosteroidów (za lek pierwszego rzutu uznano prednizon). W leczeniu stosowane są również leki biologiczne i cytostatyki. Pomimo wdrożonej terapii u części osób choroba przechodzi w postać przewlekłą, a u 5\% osób schorzenie to prowadzi do zgonu $[1,3]$.

Za kluczowe w opiece pielęgniarskiej - oprócz udziału w realizacji planu terapeutycznego - należy uznać okazywanie choremu i jego bliskim wsparcia oraz prowadzenie edukacji zdrowotnej, a także pozyskanie podopiecznego do współpracy [6-7].

\section{CEL PRACY}

Celem niniejszej pracy jest przedstawienie planu opieki nad chorym z sarkoidozą $\mathrm{z}$ uwzględnieniem Międzynarodowej Klasyfikacji Praktyki Pielęgniarskiej ICNP ${ }^{\circledast}$.

\section{MATERIAŁ I METODY}

$\mathrm{W}$ badaniach zastosowano studium indywidualnego przypadku i posłużono się zróżnicowanymi technikami gromadzenia informacji o chorym, takimi jak wywiad, obserwacja, pomiary oraz analiza dokumentacji medycznej pacjenta. $\mathrm{W}$ ocenie statusu chorego wykorzystano m.in. wystandaryzowane skale C-HOBIC.

Badanie zostało przeprowadzone w kwietniu 2019 roku na Oddziale Chorób Wewnętrznych 7 Szpitala Marynarki Wojennej w Gdańsku i objęto nim 54-letniego chorego hospitalizowanego z powodu sarkoidozy. Przed badaniem chory został poinformowany o celu badania i zapewniony o anonimowości uzyskanych danych. Na przeprowadzenie badania wyraził zgodę zarówno pacjent, jak i komendant szpitala.

\section{Opis przypadku}

Powodem zgłoszenia się pacjenta do szpitala były utrzymujące się od kilku dni stany podgorączkowe, rumień guzowaty na obu kończynach dolnych i lewej kończynie górnej, a także bóle stawów.

W dniu przyjęcia dokonano u chorego oceny tętna (80 ud/min, miarowe, dobrze napięte), ciśnienia tętniczego krwi (135/86 mmHg), temperatury ciała $(37,7 \mathrm{oC})$, masy ciała $(99 \mathrm{~kg})$ i wzrostu $(175 \mathrm{~cm})$, obliczono wskaźnik BMI $(32 \mathrm{~kg} / \mathrm{m} 2)$. Uczulenia chory zanegował, poinformował o paleniu tytoniu (od 15 lat).

Ponadto w ocenie pacjenta zaobserwowano/ stwierdzono w zakresie układu:

- oddechowego - 14 oddechów/ minutę, oddech regularny, torem brzusznym, bez udziału dodatkowych mięśni oddechowych,

- układu mięśniowo-szkieletowego - ból stawów (4/10pkt), ograniczoną ruchomość stawów dłoni,

- pokarmowego i moczowo-płciowego - nie stwierdzono nieprawidłowości.

Orientacja auto- i allopsychiczna chorego zachowana, nastrój wyrównany, pacjent zgłaszał lekki niepokój związany z hospitalizacją. Powłoki skórne chorego zadbane, czyste, skóra ciepła i wilgotna. Chory aktywny zawodowo, mieszka z rodziną, warunki socjalne określił jako zadowalające. Pacjent zdolny do samoopieki w zakresie czynności dnia codziennego.

Na podstawie skal C-HOBIC [8-9] u chorego stwierdzono: minimalne zmęczenie, duszność nieobecną przy odpoczynku, pojawiającą się przy umiarkowanej aktywności. Nudności oraz upadki w ciągu ostatnich 90 dni pacjent zanegował. Oceniając gotowość do wypisu/ samoopieki terapeutycznej stwierdzono u chorego: brak wiedzy o celu stosowanego leczenia, w pozostałych obszarach chory wykazywał umiarkowaną orientację.

$\mathrm{W}$ procesie diagnostycznym u chorego wykonano bronchofiberoskopię (zaczerwienienie błony śluzowej oskrzela górnego lewego), USG jamy brzusznej (wątroba o zwiększonej echogeniczności z cechami stłuszczenia Io), tomografię komputerową klatki piersiowej (powiększone węzły chłonne w zakresie wnęk płucnych i śródpiersia, zmiany guzkowe w miąższu płucnym o typowym rozmieszczeniu dla sarkoidozy), echokardiografię (niewielki przerost prawej komory serca), badanie krwi na obecność Yersinia entrocolita IgA (2,3/ wynik dodatni powyżej 1,1) oraz EKG i RTG klatki piersiowej (bez niepokojących zmian). Ostatecznie u pacjenta rozpoznano sarkoidozę węzłowo-płucną z zespołem Lofergena. U chorego zastosowano leczenie farmakologiczne drogą doustną: Apo-Napro (2 x $250 \mathrm{mg}$ ), Metypred (1 x $8 \mathrm{mg}$ ) oraz Controloc (1 x $20 \mathrm{mg})$. 


\section{Plan opieki pielęniarskiej z uwzględnieniem ICNP}

W niniejszym opracowaniu wykorzystano aktualną (z roku 2019) wersję słownika zawierającego referencyjną terminologię ICNP ${ }^{\circledast}$ (International Classification for Nursing Practice/ Międzynarodowa Klasyfikacja Praktyki Pielęgniarskiej) [10].

\section{Diagnoza 1. Ból stawów [10047104]}

Interwencje: Ocenianie bólu [10026119]; Zarządzanie bólem [10011660]; Administrowanie lekiem przeciwbólowym [10023084]; Nauczanie o bólu [10039115]; Leczenie bólu kontrolowane przez pielęgniarkę [10039798]

Oczekiwany wynik: Bez bólu [10029008]

Diagnoza 2. Duszność funkcjonalna (wysiłkowa) [10029414]

Interwencje: Ocenianie statusu oddechowego [10036786]; Monitorowanie statusu (wydolności) oddychania [10012196]; Zachęcanie do odpoczynku [10041415]; Nauczanie technik oddechowych [10039213]; Pozycjonowanie pacjenta [10014761]

Oczekiwany wynik: Bez duszności [10029264]

\section{Diagnoza 3. Gorączka [10041539]}

Interwencje: Zmierzenie temperatury ciała [10032006]; Monitorowanie temperatury ciała [10012165]; Nauczanie o pomiarze temperatury ciała [10044738]; Administrowanie lekiem przeciwgorączkowym [10037248]; Zarządzanie gorączką [10041721]

Oczekiwany wynik: Temperatura ciała w granicach normy [10027652]

Diagnoza 4. Zaburzony czynny zakres ruchu [10052095]

Interwencje: Ocenianie czynnego zakresu ruchu [10040044]; Promowanie ćwiczeń [10040834]; Wzmacnianie techniki wykonywania ćwiczeń mięśni lub stawów [10036512]; Promowanie przestrzegania reżimu ćwiczeń [10041628]

Oczekiwany wynik: Efektywny czynny zakres ruchu [10052082]

\section{Diagnoza 5. Zmęczenie [10000695]}

Interwencje: Ocenianie zmęczenia [10026086]; Zarządzanie zmęczeniem [10046289]; Zachęcanie do odpoczynku [10041415]; Ocenianie możliwości [10026040]

Oczekiwany wynik: Zredukowane zmęczenie [10029390]

Diagnoza 6. Ryzyko efektu ubocznego leku [10037604]

Interwencje: Ocenianie ryzyka negatywnej interakcji na lek [10045940]; Monitorowanie odpowiedzi na leczenie [10032109]; Nauczanie o efektach ubocznych leku [10044614]

Oczekiwany wynik: Bez efektu ubocznego leku [10040295]
Diagnoza 7. Brak wiedzy o chorobie [10021994]

Interwencje: Ocenianie wiedzy o chorobie [10030639]; Nauczanie o chorobie [10024116]; Ocenianie reakcji na nauczanie [10024279]

Oczekiwany wynik: Wiedza o chorobie [10023826]

Diagnoza 8. Nadużywanie tytoniu [10022247]

Interwencje: Ocenianie używania tytoniu [10038606]; Nauczanie o używaniu tytoniu [10038843]; Poradnictwo dotyczące stosowania tytoniu [10031058]; Nauczanie o rzucaniu palenia [10038647]; Ustalanie daty zaprzestania palenia [10038827]

Oczekiwany wynik: Bez nadużywania tytoniu [10029147]

\section{Diagnoza 9. Nadwaga [10027300]}

Interwencje: Ważenie pacjenta [10033323]; Monitorowanie wagi ciała [10032121]

Nauczanie o efektywnej wadze ciała [10033001]

Oczekiwany wynik: Waga w granicach normy [10027392]

\section{OMÓWIENIE}

Już w roku 1946 Sven Löfgren stwierdził, że we wczesnej fazie sarkoidozy może występować powiększenie węzłów wnęk płuc, rumień guzowaty, zmiany w stawach i podwyższona temperatura ciała $[1,3,5]$. Pełną manifestację kliniczną ww. symptomów prezentował również pacjent opisany w niniejszym artykule.

Wprawdzie u wielu chorych dochodzi do samoistnego ustąpienia zmian, to jednak w przebiegu sarkoidozy mogą rozwinąć się powikłania obejmujące przede wszystkim uszkodzenia: płuc, oczu (utratę wzroku, zaćmę lub jaskrę), serca (zaburzenia rytmu serca), czy nerwów [11-14]. U pacjenta wykonano zalecane w przypadku sarkoidozy badania diagnostyczne $[2,5]$, a ich wyniki potwierdziły występowanie zaburzeń głównie w funkcjonowaniu układu oddechowego, wątroby oraz serca. Zadaniem opiekującego się pacjentem personelu pielęgniarskiego było m.in. przygotowanie i towarzyszenie choremu podczas wykonywania tych badań oraz realizowanie planu terapeutycznego.

Sarkoidoza, stanowiąc schorzenie o stosunkowo niepewnym odległym rokowaniu, może wpływać negatywnie na stan psychiczny chorego, sprzyjając depresji i obniżeniu jakości życia, a także występowaniu przewlekłego zmęczenia [15-16]. Niektórzy łączą występowanie przytoczonych problemów z niskim statusem społeczno-ekonomicznym chorych [17]. Opisany pacjent wprawdzie prezentował wyrównany nastrój oraz deklarował wsparcie bliskich, ale zgłaszał zmęczenie oraz niepokój związany z koniecznością hospitalizacji.

Zindywidualizowane i holistyczne pielęgnowanie chorego z rozpoznaną sarkoidozą powinno uwzględniać zarówno manifestację kliniczną i stopień zaawansowania choroby, plan diagnostyczno-terapeutyczny, jak i zasoby samoopiekuńcze pacjenta, a także ryzyko rozwoju powikłań oraz poprawę jakości życia pacjenta. 


\section{WNIOSKI}

W wyniku przeprowadzonej oceny i analizy statusu pacjenta sformułowano 7 charakterystycznych dla sarkoidozy diagnoz pielęgniarskich, obejmujących: ból stawów, duszność funkcjonalną, gorączkę, zaburzony czynny zakres ruchu, zmęczenie, ryzyko efektu ubocznego leku i brak wiedzy o chorobie oraz 2 diagnozy wynikające ze stylu życia chorego: nadużywanie tytoniu oraz nadwagę.

W planowaniu opieki uwzględniono kluczowe dla ww. diagnoz interwencje, dotyczące monitorowania symptomów i wskaźników zdrowotnych chorego oraz oceny jego wiedzy, a także udział pielęgniarki w procesie terapeutycznym. Słownik ICNP ${ }^{\circledast}$ posiada wystarczający zasób terminów, umożliwiających stworzenie satysfakcjonującego planu opieki pielęgniarskiej nad chorym z sarkoidozą.

\section{REFERENCES/PIŚMIENNICTWO}

1. Zdrojewski Z, Wierzba K. Sarkoidoza - choroba wielonarządowa. Forum Reumatol. 2018;4 (4): 225-230.

2. Stefański M, Stefańska M, Bruliński K. Etiologia, patogeneza i diagnostyka sarkoidozy - przegląd piśmiennictwa. Medycyna Rodzinna. 2016; 2: 98-105.

3. Kempisty A. Sarkoidoza. Postępy Nauk Medycznych. 2011;24 (4): 286-294.

4. Kiszałkiewicz J, Piotrowski WJ, Brzeziańska-Lasota E. Selected molecular events in the pathogenesis of sarcoidosis - recent advances. Pneumonol Alergol Pol. 2015;83(6): 462-475. D0I: 10.5603 / PiAP.2015.0076.

5. Ziora D, Jastrzębski D, Labus Ł. Postępy w diagnostyce sarkoidozy płuc. Pneumonol Alergol Pol. 2012;80 (4): 355-364.

6. Page M. Nursing care and management of patients with sarcoidosis. Br J Nurs. 2008;17 (4): 252-7. D0l: 10.12968/bjon.2008.17.4.28714.

7. Jeny $F$, Bouvry $D$, Freynet 0 , Soussan $M$, et al. Management of sarcoidosis in clinical practice. European Respiratory Review 2016; 25: 141-150; D0l: 10.1183/16000617.0013-2016.

8. Canadian Health Outcomes for Better Information and Care Project [https://c-hobic cna-aiic.ca/about/default_e.aspx-dostęp 09.05.2019].

9. Andruszkiewicz A. Studium przypadku HOBIC. [w]: Kilańska D, Grabowska H, Gaworska-Krzemińska A, red. E-zdrowie. Wprowadzenie do informatyki w pielęgniarstwie. Warszawa: Wydawnictwo Lekarskie PZWL; 2018, s.236-265.

10. ICNP Browser [https://www.icn.ch/what-we-do/projects/ehealth/icnp-browser dostęp 15.06.2019].

11. Błaut-Jurkowska J, Podolec $P$, Olszowska M. Sarkoidoza serca - obraz kliniczny i rozpoznanie. Polski Merkuriusz Lekarski. 2016; 41: 101-106.

12. Załęska $M$, Błasińska-Przerwa $K$, Oniszh $K$, i wsp. Włóknienie śródpiersia z nadciśnieniem płucnym jako rzadkie powikłanie sarkoidozy. Pneumonol Alergol Pol. 2013; 81: 273-280.

13. Błaszczyk M. Sarkoidoza skórna - różnorodność kliniczna i trudności diagnostyczne. Przegląd Dermatologiczny. 2012; 99: 185-194.

14. Brola W, Pejas-Dulewicz R, Wasiński J, Fudala M. Neurosarcoidosis. Studia Medyczne. 2014; 30: 51-56.

15. Górski W, Piotrowski WJ. Zespół zmęczenia w przebiegu sarkoidozy. Pneumono Alergol Pol. 2016;84 (4):244-250. D0I: 10.5603/PiAP.2016.0030.

16. Zieleźnik $K$, Jastrzębski $D$, Ziora D. Fatigue in patients with inactive sarcoidosis does not correlate with lung ventilation ability or walking distance. Pilot Study. Pneumonol Alergol Pol. 2015;83 (1):14-22. D0l: 10.5603/PiAP.2015.0002.

17. Sahni S, Talwar A, Khanijo S, Talwa A. Socioeconomic status and its relationship to chronic respiratory disease. Advances in Respiratory Medicine 2017; 85: 97-108.

Manuscript received/Praca zgłoszona do czasopisma: 05.10.2019

Manuscript accepted/Praca zaakceptowana do druku: 20.11.2019

Translation/Tłumaczenie: Art of Translation/BABEL ul. Kościuszki 61, 81-703, Sopot 